Article

\title{
Comparing the Effect of Dipeptidyl-Peptidase 4 Inhibitors and Sulfonylureas on Albuminuria in Patients with Newly Diagnosed Type 2 Diabetes Mellitus: A Prospective Open-Label Study
}

\author{
Po-Chung Cheng ${ }^{1}$, Shang-Ren Hsu ${ }^{1}$, Jeng-Fu Kuo ${ }^{1}$, Yun-Chung Cheng ${ }^{2}$, Yu-Hsiu Liu ${ }^{3}$ and \\ Shih-Te Tu ${ }^{1, *}$ \\ 1 Division of Endocrinology and Metabolism, Department of Internal Medicine, Changhua Christian Hospital, \\ 135 Nanxiao Street., Changhua City, Changhua County 500, Taiwan; 180459@cch.org.tw (P.-C.C.); \\ 67781@cch.org.tw (S.-R.H.); 103348@cch.org.tw (J.-F.K.) \\ 2 Department of Radiology, Taichung Veterans General Hospital, Taichung Veterans General Hospital, \\ Section 4, No. 1650, Taiwan Boulevard, Taichung, Taiwan; iancheng@vghtc.gov.tw \\ 3 Department of Accounting and Information Systems, National Taichung University of Science and \\ Technology, 129 San Min Road., Taichung, Taiwan; graceliu@nutc.edu.tw \\ * Correspondence: 10836@cch.org.tw
}

Received: 11 August 2019; Accepted: 15 October 2019; Published: 17 October 2019

\begin{abstract}
Diabetic kidney disease (DKD) leads to substantial morbidity in patients with type 2 diabetes mellitus (T2DM). Evidence suggests that antidiabetic drug dipeptidyl-peptidase 4 (DPP-4) inhibitors may be able to attenuate albuminuria, whereas the influence of sulfonylureas on albuminuria remains unclear. This prospective open-label study investigated the effect of DPP-4 inhibitors and sulfonylureas on urinary albumin excretion, which is a marker of renal microvascular abnormality. A total of 101 participants with newly diagnosed T2DM were enrolled. In addition to metformin therapy, 45 patients were assigned to receive DPP-4 inhibitors and 56 to receive sulfonylureas. Urinary albumin-to-creatinine ratio (ACR) was significantly reduced in recipients of DPP-4 inhibitors after 24 weeks $(29.2 \mu \mathrm{g} / \mathrm{mg}$ creatinine vs. $14.9 \mu \mathrm{g} / \mathrm{mg}$ creatinine, $P<0.001)$, whereas urinary ACR was not significantly changed by sulfonylureas $(39.9 \mu \mathrm{g} / \mathrm{mg}$ creatinine vs. $43.2 \mu \mathrm{g} / \mathrm{mg}$ creatinine, $P=0.641)$. The effect on albuminuria occurred even though both treatment groups had a similar change in serum glycated hemoglobin $\mathrm{A}_{1 \mathrm{c}}(-1.87 \%$ vs. $-2.40 \%, P=0.250)$. Therefore, in diabetic patients the addition of DPP-4 inhibitors lowered urinary albumin excretion compared to sulfonylureas, and attenuation of albuminuria may be a consideration when choosing between antidiabetic medications.
\end{abstract}

Keywords: proteinuria; diabetes mellitus; dipeptidyl-peptidase 4 inhibitors; sulfonylureas

\section{Introduction}

Diabetic kidney disease (DKD) occurs in up to $40 \%$ of patients with type 2 diabetes mellitus (T2DM) [1]. DKD leads to substantial morbidity and reduces quality of life in affected patients [2] and chronic hyperglycemia in the context of T2DM leads to microvascular injury in the diabetic kidney [3]. Current evidence suggests that clinical interventions targeting plasma glucose, body weight, and blood pressure can attenuate the development of DKD [4].

Oral antidiabetic drugs such as dipeptidyl-peptidase 4 (DPP-4) inhibitors and sulfonylureas are extensively used in the treatment of T2DM. Although both DPP-4 inhibitors and sulfonylureas effectively lower plasma glucose levels, there may be differences in their effect on the diabetic kidney. Importantly, clinical evidence has suggested that DPP-4 inhibitors may be able to attenuate the 
progression of albuminuria in patients with T2DM [5,6]. In contrast, there is insufficient information regarding the effect of sulfonylureas on DKD. However, sulfonylureas are associated with weight gain and heart dysfunction [7], both of which may worsen albuminuria in diabetic patients.

Considering that both DPP-4 inhibitors and sulfonylureas have a distinct effect on body weight and blood pressure, we hypothesized that these medications may influence the diabetic kidney differently. This study investigated the effect of DPP-4 inhibitors and sulfonylureas on urinary albumin excretion, a marker of renal microvascular abnormality, in patients with newly diagnosed T2DM. Moreover, the effect of these medications on clinical variables including body weight, serum glycated hemoglobin $\mathrm{A}_{1 \mathrm{c}}\left(\mathrm{HbA}_{1 \mathrm{c}}\right)$, and systolic blood pressure were examined.

\section{Materials and Methods}

\subsection{Participant Selection}

In this prospective study, diabetic patients who visited the Endocrinology clinic between March 2016 and February 2018 were screened for eligibility. Inclusion criteria were patients exceeding 20 years of age, with newly diagnosed T2DM, who had yet to receive antidiabetic medications. Exclusion criteria were patients with non-diabetic kidney disease, congenital kidney abnormalities, or end-stage renal disease. Moreover, patients receiving angiotensin-converting enzyme inhibitors (ACEI) or angiotensin receptor blockers (ARB) were ineligible because these medications can modify urinary albumin excretion.

\subsection{Study Protocol}

Demographic information, including age, sex, and systolic blood pressure, was recorded at the initial clinic visit. In accordance with the recommendation by the American Diabetes Association to prescribe metformin to all patients with T2DM in the absence of contraindications [5], participants received $1000 \mathrm{mg}$ of metformin therapy at the beginning of the study. Subsequently, patients were assigned to receive either the DPP-4 inhibitor Vildagliptin $50 \mathrm{mg}$ twice daily or the sulfonylurea Glimepiride $2 \mathrm{mg}$ twice daily. Treatment allocation was made by a committee of endocrinologists to match participants in the treatment groups by age, body weight, serum $\mathrm{HbA}_{1 \mathrm{c}}$, urinary albumin-to-creatinine ratio (ACR), and serum creatinine. Both the investigators and the participants were informed of the treatment allocation. Participants subsequently received standard clinical care, including medical nutrition therapy and diabetes educator consultation, in accordance with current diabetes management guidelines [5].

\subsection{Laboratory Methods}

At the initial clinic visit, participants received blood tests for serum $\mathrm{HbA}_{1 \mathrm{c}}$, serum creatinine, serum alanine transferase, and plasma lipid profile after a 12-hour fast. Blood tests for these clinical variables were repeated after 24 weeks of pharmacologic treatment. Blood samples were delivered to the clinical laboratory within one hour of venous sampling and assayed by Beckman Coulter UniCel DXC 800 Synchron $^{\mathrm{TM}}$ Clinical Systems (Beckman Coulter, Brea, USA). The analytical precision was within $1.7 \mathrm{mg} / \mathrm{dL}$ for high-density lipoprotein cholesterol, within $3.0 \mathrm{mg} / \mathrm{dL}$ for low-density lipoprotein cholesterol, within $7.5 \mathrm{mg} / \mathrm{dL}$ for triglycerides, and within $0.1 \%$ for serum $\mathrm{HbA}_{1 \mathrm{c}}$. For the purpose of this study, the estimated glomerular filtration rate (eGFR) was calculated using the Modification of Diet in Renal Disease equation [8].

For each participant, urine samples were collected in the morning after a 12-hour fast at the first clinic visit and after 24 weeks of pharmacologic therapy. The urinary ACR was measured by the turbidimetric method using Beckman Coulter UniCel DXC 800 Synchron ${ }^{\mathrm{TM}}$ Clinical Systems (Beckman Coulter, Brea, USA). The analytical precision for urinary ACR was within $2.3 \mathrm{ug} / \mathrm{mg}$ creatinine. 


\subsection{Outcome Measures}

The primary outcome measure of this study was the change in urinary ACR after completing 24 weeks of pharmacologic treatment. The changes in serum $\mathrm{HbA}_{1 \mathrm{c}}$, body weight, serum creatinine level, eGFR, and systolic blood pressure were considered secondary outcome measures.

\subsection{Ethical Approval}

This study was carried out in accordance with the World Medical Association's Declaration of Helsinki. The study was approved by the Institutional Review Board of Changhua Christian Hospital (CCH IRB Identifier: 190512) and listed in a clinical trial registry (ClinicalTrials.gov Identifier: NCT03983551). All participants provided written informed consent to participate in the study in accordance with the Declaration of Helsinki.

\subsection{Statistical Analysis Plan}

A power analysis suggested that a sample size of 22 participants in each treatment group would be necessary to detect a significant change in urinary ACR from baseline with $80 \%$ statistical power, and the anticipated treatment effect size, expressed as the Cohen's $d$ coefficient, was 0.5 . The treatment groups included all participants who received at least one dose of antidiabetic medication. The first laboratory test prior to pharmacologic intervention was considered as the baseline. Outcome measures in this study were based on laboratory data after 24 weeks of pharmacologic therapy. Participants who missed the follow up or withdrew from the study were assessed by an intention to treat analysis.

The demographic characteristics and clinical outcomes of the treatment groups were compared using a Student's independent $t$-test for continuous variables and Pearson's $\chi^{2}$-test for categorical variables. A dependent $t$-test was used to compare the changes in urinary $\mathrm{ACR}$, serum $\mathrm{HbA}_{1 c}$, body weight, and serum creatinine relative to baseline levels. A statistical analysis was performed using IBM SPSS version 22.0 (IBM SPSS Statistics for Windows, New York, USA). A two-tailed $P$ value of less than 0.05 indicated statistical significance.

\section{Results}

This study screened 120 patients for eligibility. Eleven patients were excluded due to concomitant use of ACEI or ARB, and eight were ineligible because they were previously diagnosed with non-diabetic kidney disease. The enrollment process is illustrated in Figure 1. 




Figure 1. Enrollment protocol of the study. ACEI: angiotensin-converting enzyme inhibitors, ARB: angiotensin receptor blockers.

\subsection{Demographic Characteristics of Participants}

The study enrolled 101 participants, with 45 recipients of DPP-4 inhibitors and 56 of sulfonylureas. Their demographic features are summarized in Table 1. Both treatment groups had comparable mean age (62.9 years vs. 64.3 years, $P=0.5$ ), body weight ( $68.5 \mathrm{~kg}$ vs. $66.2 \mathrm{~kg}, P=0.48$ ), systolic blood pressure (134 mm Hg vs. $133 \mathrm{~mm} \mathrm{Hg}, P=0.802)$, and serum $\mathrm{HbA}_{1 \mathrm{c}}(8.7 \%$ vs. $8.9 \%, P=0.66)$. Moreover, participants in both groups had similar mean urinary ACR at diagnosis $(29.2 \mu \mathrm{g} / \mathrm{mg}$ creatinine vs. $39.9 \mu \mathrm{g} / \mathrm{mg}$ creatinine, $P=0.157)$. Similar proportions of patients in both treatment groups received antihypertensive medications including calcium channel blockers ( $26.7 \%$ vs. $37.5 \%$, $P=0.249)$, beta blockers $(24.4 \%$ vs. $17.8 \%, P=0.418)$, and diuretics $(6.7 \%$ vs. $7.1 \%, P=0.925)$. Patients receiving ACEI or ARB were ineligible because these medications can modify urinary albumin excretion. All participants completed the 24-week clinical trial without loss of follow-up. 
Table 1. Demographic features of participants at diagnosis of type 2 diabetes mellitus.

\begin{tabular}{|c|c|c|c|}
\hline Variables & $\begin{array}{l}\text { DPP-4 Inhibitors + } \\
\text { Metformin }(n=45)\end{array}$ & $\begin{array}{c}\text { Sulfonylureas }+ \\
\text { Metformin }(n=56)\end{array}$ & $P$ Value \\
\hline Age (years) & $62.9 \pm 14.0$ & $64.3 \pm 10.7$ & 0.500 \\
\hline Sex (Female) & $22(52.4 \%)$ & $25(47.2 \%)$ & 0.682 \\
\hline Body weight (kg) & $68.5 \pm 16.0$ & $66.2 \pm 15.1$ & 0.48 \\
\hline Serum $\mathrm{HbA}_{1 \mathrm{c}}(\%)$ & $8.7 \pm 1.9$ & $8.9 \pm 1.8$ & 0.66 \\
\hline Creatinine $(\mathrm{mg} / \mathrm{dL})$ & $0.83 \pm 0.19$ & $0.86 \pm 0.25$ & 0.379 \\
\hline Estimated GFR $\left(\mathrm{mL} / \mathrm{min} / 1.73 \mathrm{~m}^{2}\right)$ & $88.5 \pm 24.8$ & $89.6 \pm 26.7$ & 0.843 \\
\hline $\operatorname{ALT}(\mathrm{U} / \mathrm{mL})$ & $33.0 \pm 29.5$ & $28.8 \pm 22.1$ & 0.430 \\
\hline Systolic blood pressure (mm Hg) & $134 \pm 19.4$ & $133 \pm 14.8$ & 0.802 \\
\hline Urinary ACR ( $\mu \mathrm{g} / \mathrm{mg}$ creatinine) & $29.2 \pm 31.2$ & $39.9 \pm 41.9$ & 0.157 \\
\hline Triglycerides (mg/dL) & $162 \pm 118$ & $189 \pm 116$ & 0.278 \\
\hline High density lipoprotein cholesterol (mg/dL) & $44.2 \pm 12.3$ & $46.3 \pm 14.3$ & 0.455 \\
\hline Low density lipoprotein cholesterol (mg/dL) & $110 \pm 34.8$ & $117 \pm 32.7$ & 0.277 \\
\hline Use of calcium channel blockers & $12(26.7 \%)$ & $21(37.5 \%)$ & 0.249 \\
\hline Use of beta blockers & $11(24.4 \%)$ & $10(17.8 \%)$ & 0.418 \\
\hline Use of diuretics & $3(6.7 \%)$ & $4(7.1 \%)$ & 0.925 \\
\hline
\end{tabular}

Data are expressed as means with a standard deviation of the mean for continuous variables and number (\%) for categorical variables. Variables are compared between groups using Student's $t$-test for continuous data. ALT: alanine aminotransferase, $\mathrm{HbA}_{1 \mathrm{c}}$ : glycosylated hemoglobin $\mathrm{A}_{1 \mathrm{c}}$, ACR: albumin-to-creatinine ratio, DPP-4: dipeptidyl-peptidase 4, GFR: glomerular filtration rate.

\subsection{Comparison of the Clinical Outcomes Relative to Baseline Levels}

After 24 weeks of antidiabetic therapy, urinary ACR was significantly reduced in recipients of DPP-4 inhibitors relative to baseline levels $(29.2 \mu \mathrm{g} / \mathrm{mg}$ creatinine vs. $14.9 \mu \mathrm{g} / \mathrm{mg}$ creatinine, $P<0.001)$. In contrast, urinary albumin excretion was not significantly influenced by sulfonylureas relative to levels at diagnosis $(39.9 \mu \mathrm{g} / \mathrm{mg}$ creatinine vs. $43.2 \mu \mathrm{g} / \mathrm{mg}$ creatinine, $P=0.641)$. Moreover, body weight was slightly reduced relative to baseline in recipients of DPP-4 inhibitors ( $68.5 \mathrm{~kg}$ vs. $67.4 \mathrm{~kg}$, $P=0.0169)$ but remained unchanged in the sulfonylurea group $(66.2 \mathrm{~kg}$ vs. $66.4 \mathrm{~kg}, P=0.868)$. In both treatment groups, serum creatinine, eGFR, and systolic blood pressure were not significantly affected by antidiabetic therapy. These findings are recorded in Table 2 .

Table 2. Comparison of outcome measures relative to levels at diagnosis.

\begin{tabular}{ccc}
\hline Treatment Duration & DPP-4 Inhibitors + Metformin $(\boldsymbol{n = 4 5 )}$ & Sulfonylureas + Metformin $(\boldsymbol{n}=\mathbf{5 6})$ \\
\hline Urinary ACR $(\mu \mathrm{g} / \mathrm{mg}$ creatinine $)$ & & \\
0 week & $29.2 \pm 31.2$ & $39.9 \pm 41.9$ \\
24 weeks & $14.9 \pm 23.9$ & $43.2 \pm 64.2$ \\
$P$ value & $<0.001$ & 0.641 \\
\hline Serum $\mathrm{HbA}_{1 \mathrm{c}}(\%)$ & & \\
0 week & $8.7 \pm 1.9$ & $8.9 \pm 1.8$ \\
24 weeks & $6.8 \pm 0.83$ & $7.2 \pm 1.0$ \\
$P$ value & $<0.001$ & $<0.001$ \\
\hline Body weight $(\mathrm{kg})$ & & \\
0 week & $68.5 \pm 16.0$ & $66.2 \pm 15.1$ \\
24 weeks & $67.4 \pm 15.8$ & $66.4 \pm 14.4$ \\
$P$ value & 0.0169 & 0.868 \\
\hline Seatinine $(\mathrm{mg} / \mathrm{dL})$ & & \\
24 week & $0.83 \pm 0.19$ & $0.86 \pm 0.24$ \\
$P$ value & $0.85 \pm 0.28$ & $0.95 \pm 0.35$ \\
\hline
\end{tabular}


Table 2. Cont.

\begin{tabular}{ccc}
\hline Treatment Duration & DPP-4 Inhibitors + Metformin $(n=45)$ & Sulfonylureas + Metformin $(n=56)$ \\
\hline Estimated GFR $\left(\mathrm{mL} / \mathrm{min} / 1.73 \mathrm{~m}^{2}\right)$ & & \\
0 week & $88.5 \pm 24.8$ & $89.6 \pm 26.7$ \\
24 weeks & $97.5 \pm 47.5$ & $84.6 \pm 30.3$ \\
$P$ value & 0.233 & 0.225 \\
\hline Systolic blood pressure $(\mathrm{mm} \mathrm{Hg})$ & & \\
0 week & $134 \pm 19.4$ & $133 \pm 14.8$ \\
24 weeks & $128 \pm 13.2$ & $131 \pm 10.6$ \\
$P$ value & 0.113 & 0.56 \\
\hline
\end{tabular}

Data are expressed as means with a standard deviation of the mean for continuous variables. Variables are compared to baseline levels using the paired $t$-test. $\mathrm{HbA}_{1 \mathrm{c}}$ : glycosylated hemoglobin $\mathrm{A}_{1 \mathrm{c}}, \mathrm{ACR}$ : albumin-to-creatinine ratio, kg: kilograms, mg/dL: milligrams per deciliter, mm Hg: millimeters of mercury, DPP-4: dipeptidyl-peptidase 4, GFR: glomerular filtration rate.

\subsection{Comparison of the Clinical Outcomes between DPP-4 Inhibitors and Sulfonylureas}

In terms of the primary outcome measure, participants who received DPP-4 inhibitors had a significant reduction in urinary ACR relative to recipients of sulfonylureas $(-14.3 \mu \mathrm{g} / \mathrm{mg}$ creatinine vs. $3.29 \mu \mathrm{g} / \mathrm{mg}$ creatinine, $P=0.037)$. Regarding the secondary outcome measures, both groups demonstrated comparable changes in serum $\mathrm{HbA}_{1 \mathrm{c}}(-1.87 \%$ vs. $-2.40 \%, P=0.250)$, body weight $(-1.04 \mathrm{~kg}$ vs. $0.12 \mathrm{~kg}, P=0.203)$, serum creatinine $(-0.01 \mathrm{mg} / \mathrm{dL}$ vs. $0.08 \mathrm{mg} / \mathrm{dL}, P=0.171)$, eGFR $\left(8.94 \mathrm{~mL} / \mathrm{min} / 1.73 \mathrm{~m}^{2}\right.$ vs. $\left.-4.93 \mathrm{~mL} / \mathrm{min} / 1.73 \mathrm{~m}^{2}, P=0.104\right)$ and systolic blood pressure $(-4.27 \mathrm{~mm}$ $\mathrm{Hg}$ vs. $-1.14 \mathrm{~mm} \mathrm{Hg}, P=0.333)$ after 24 weeks of antidiabetic therapy. These findings are shown in Table 3.

Table 3. Comparison of outcome measures between dipeptidyl-peptidase 4 inhibitors and sulfonylureas.

\begin{tabular}{|c|c|c|c|}
\hline Treatment Duration & $\begin{array}{l}\text { DPP-4 Inhibitors + } \\
\text { Metformin }(n=45)\end{array}$ & $\begin{array}{c}\text { Sulfonylureas }+ \\
\text { Metformin }(n=56)\end{array}$ & $P$ Value \\
\hline \multicolumn{4}{|l|}{ Change in urinary ACR ( $\mu \mathrm{g} / \mathrm{mg}$ creatinine) } \\
\hline 24 weeks & $-14.3 \pm 21.2$ & $3.29 \pm 52.5$ & 0.037 \\
\hline \multicolumn{4}{|l|}{ Change in serum $\mathrm{HbA}_{1 \mathrm{c}}(\%)$} \\
\hline 24 weeks & $-1.87 \pm 2.00$ & $-2.40 \pm 2.43$ & 0.250 \\
\hline \multicolumn{4}{|l|}{ Change in body weight $(\mathrm{kg})$} \\
\hline 24 weeks & $-1.04 \pm 2.82$ & $0.12 \pm 5.55$ & 0.203 \\
\hline \multicolumn{4}{|l|}{ Change in serum creatinine $(\mathrm{mg} / \mathrm{dL})$} \\
\hline 24 weeks & $-0.01 \pm 0.359$ & $0.08 \pm 0.32$ & 0.171 \\
\hline \multicolumn{4}{|l|}{ Change in estimated GFR $\left(\mathrm{mL} / \mathrm{min} / 1.73 \mathrm{~m}^{2}\right)$} \\
\hline 24 weeks & $8.94 \pm 49.6$ & $-4.93 \pm 30.0$ & 0.104 \\
\hline \multicolumn{4}{|l|}{ Change in systolic blood pressure (mm Hg) } \\
\hline 24 weeks & $-4.27 \pm 17.7$ & $-1.14 \pm 14.6$ & 0.333 \\
\hline
\end{tabular}

\section{Discussion}

As observed in this study, DPP-4 inhibitors significantly lowered urinary albumin excretion in diabetic patients after 24 weeks of therapy. In contrast, sulfonylureas had no significant effect on urinary ACR despite their glucose-lowering capacity. Moreover, recipients of DPP-4 inhibitors demonstrated a significantly reduced body weight. Since both treatment groups attained comparable levels of serum $\mathrm{HbA}_{1 \mathrm{c}}$ at study completion, the effect of DPP-4 inhibitors on albuminuria may involve pathways in addition to glycemic control. 
However, this study did not detect a significant effect of either DPP-4 inhibitors or sulfonylureas on eGFR in diabetic patients. Specifically, albuminuria is often considered an early manifestation of DKD that precedes the decline in eGFR [9], and whether a reduction in albuminuria in recipients of DPP-4 inhibitors will lead to preservation of eGFR requires a longer observation time.

Several randomized clinical studies have shown that DPP-4 inhibitors may reduce albuminuria compared to placebo in patients with T2DM. In the CARMELINA study, the DPP-4 inhibitor Linagliptin attenuated albuminuria progression compared to placebo but did not have a significant effect on eGFR [10]. Similarly, in the SAVOR-TIMI study, Saxagliptin improved urinary ACR in diabetic patients without affecting their eGFR levels [11]. In a prospective clinical study, patients receiving Sitagliptin also demonstrated a significant reduction in albuminuria [12]. Overall, pharmacologic agents targeting the DPP-4 enzyme appear to have a beneficial effect on albuminuria in patients with T2DM.

DPP-4 inhibitors may attenuate the progression of albuminuria through several mechanisms. Investigators have documented an anti-inflammatory effect of DPP-4 inhibitors that can protect renal tubular cells from damage [13]. These medications may lower oxidative stress and improve endothelial function in the kidney [14], thereby reducing the detrimental effect of chronic hyperglycemia on urinary albumin excretion. Moreover, DPP-4 inhibitors have been shown to prevent kidney fibrosis in patients with longstanding T2DM [15].

In a previous study, patients receiving sulfonylureas experienced faster deterioration of kidney function compared to recipients of metformin therapy, presumably through an increase in body mass index and systolic blood pressure [16]. Another investigation reported an increase in albuminuria in recipients of gliclazide, although the underlying mechanism remains elusive [17]. Overall, sulfonylureas may have a neutral effect on DKD due to its propensity to increase body weight and blood pressure, which counteracts the protective effect of glucose-lowering in diabetic patients.

As shown in this clinical trial, DPP-4 inhibitors significantly lowered serum $\mathrm{HbA}_{1 \mathrm{c}}$ in patients with newly diagnosed T2DM. As established in previous studies, an improvement in hyperglycemia offers substantial defense against the development and progression of microalbuminuria in the diabetic kidney [18]. Furthermore, this investigation demonstrates a significant, albeit modest, effect of DPP-4 inhibitors on weight reduction. Obesity can induce glomerular hypertrophy in diabetes and accelerate the development of microalbuminuria [19]. The current study did not show an effect of this medication on blood pressure, which is another important determinant of DKD [20]. Therefore, in the context of this study DPP-inhibitors may lower albuminuria through their glucose-lowering effect and weight reduction.

The observation that DPP-4 inhibitors can reduce albuminuria in diabetic patients has clinical implications. Given the insidious course and heterogeneous presentation of DKD [21], intervention to reduce urinary albumin excretion may improve the clinical outcome. The DPP-4 inhibitor is already a favorable antidiabetic medication due to its neutral effect on body weight and relatively low risk of hypoglycemia. In addition, this study shows the beneficial effect of DPP-4 inhibitors on body weight and urinary ACR relative to sulfonylureas. Therefore, attenuation of albuminuria may be an additional consideration when selecting an antidiabetic medication.

To our knowledge, this is the first study to directly compare DPP-4 inhibitors and sulfonylureas with the primary outcome of albuminuria reduction. This study reduces the potential confounding effect of previous antidiabetic mediations on albuminuria by enrolling patients with newly diagnosed T2DM. Moreover, participants had comparable levels of serum $\mathrm{HbA}_{1 \mathrm{c}}$ after antidiabetic therapy, which may lessen any confounding effect of glucose-lowering on urinary albumin excretion. Finally, recipients of ACEI or ARB were excluded due to the established effect of these medications on urinary albumin excretion.

Nonetheless, the study design has limitations. Metformin also attenuates albuminuria by reducing oxidative stress and mesangial cell apoptosis [22]. Since all participants received metformin in addition to either DPP-4 inhibitors or sulfonylureas, a beneficial effect of metformin on urinary ACR becomes a potential confounding factor. Moreover, epidemiological evidence has suggested a strong 
genetic basis for DKD [23], but a family history of kidney disease was not accounted for in this study. Previous investigators have proposed that since hyperglycemia can accelerate urinary albumin excretion [24], the influence of antidiabetic medications on albuminuria may still partly depend on their glucose-lowering capacity. Finally, the non-randomized design and relatively small sample size may limit the robustness of this study. Randomized studies with a larger sample size will be necessary to confirm the findings of this investigation.

\section{Conclusions}

In conclusion, the addition of DPP-4 inhibitors to metformin therapy in patients with T2DM significantly reduced urinary albumin excretion relative to recipients of sulfonylureas. Importantly, the beneficial effect of DPP-4 inhibitors occurred despite attaining similar levels of glycemic control as sulfonylureas. Overall, DPP-4 inhibitors may have a role in attenuating the progression of albuminuria, and albuminuria reduction may be an additional consideration when choosing between antidiabetic medications.

Author Contributions: Conceptualization, P.-C.C., J.-F.K. and S.-T.T.; Formal analysis, Y.-C.C. and Y.-H.L.; Funding acquisition, S.-R.H.; Investigation, P.-C.C., S.-R.H., J.-F.K. and S.-T.T.; Methodology, P.-C.C., J.-F.K., Y.-H.L. and S.-T.T.; Project administration, S.-T.T.; Resources, S.-R.H. and S.-T.T.; Software, Y.-C.C.; Supervision, S.-T.T.; Validation, P.-C.C., S.-R.H., J.-F.K. and S.-R.H.; Visualization, Y.-C.C.; Writing—original draft, P.-C.C.; Writing-review \& editing, P.-C.C., S.-R.H., J.-F.K. and S.-T.T. P.-C.C. and Y.-C.C. contributed equally to this study as first authors.

Funding: This research received no external funding.

Acknowledgments: The authors would like to thank diabetes educators for providing nutrition consultation to participants in this study.

Conflicts of Interest: The authors declare no conflict of interest.

\section{References}

1. Park, C.W. Diabetic kidney disease: From epidemiology to clinical perspectives. Diabetes Metab. J. 2014, 38, 252-260. [CrossRef] [PubMed]

2. Stanton, R.C. Clinical challenges in diagnosis and management of diabetic kidney disease. Am. J. Kidney Dis. 2014, 63, 3-21. [CrossRef] [PubMed]

3. Rask-Madsen, C.; King, G.L. Vascular complications of diabetes: Mechanisms of injury and protective factors. Cell. Metab. 2013, 17, 20-33. [CrossRef] [PubMed]

4. Kim, M.K. Treatment of diabetic kidney disease: Current and future targets. Korean J. Intern. Med. 2017, 32, 622-630. [CrossRef]

5. American Diabetes Association. Introduction: Standards of Medical Care in Diabetes-2018. Diabetes Care 2018, 41, S1-S2. [CrossRef]

6. Davidson, J.A. The placement of DPP-4 inhibitors in clinical practice recommendations for the treatment of type 2 diabetes. Endocr. Pract. 2013, 19, 1050-1061. [CrossRef] [PubMed]

7. Sola, D.; Rossi, L.; Schianca, G.P.; Maffioli, P.; Bigliocca, M.; Mella, R.; Corliano, F.; Fra, G.P.; Bartoli, E.; Derosa, G. Sulfonylureas and their use in clinical practice. Arch. Med. Sci. 2015, 11, 840-848. [CrossRef]

8. Levey, A.S.; Bosch, J.P.; Lewis, J.B.; Greene, T.; Rogers, N.; Roth, D. A more accurate method to estimate glomerular filtration rate from serum creatinine: A new prediction equation. Modification of Diet in Renal Disease Study Group. Ann. Intern. Med. 1999, 130, 461-470. [CrossRef]

9. Roshan, B.; Stanton, R.C. A story of microalbuminuria and diabetic nephropathy. J. Nephropathol. 2013, 2, 234-240.

10. Rosenstock, J.; Perkovic, V.; Johansen, O.E.; Cooper, M.E.; Kahn, S.E.; Marx, N.; Alexander, J.H.; Pencina, M.; Toto, R.D.; Wanner, C.; et al. Effect of Linagliptin vs. Placebo on Major Cardiovascular Events in Adults with Type 2 Diabetes and High Cardiovascular and Renal Risk: The CARMELINA Randomized Clinical Trial. JAMA 2019, 321, 69-79. [CrossRef]

11. Mosenzon, O.; Leibowitz, G.; Bhatt, D.L.; Cahn, A.; Hirshberg, B.; Wei, C.; Im, K.; Rozenberg, A.; Yanuv, I.; Stahre, C.; et al. Effect of Saxagliptin on Renal Outcomes in the SAVOR-TIMI 53 Trial. Diabetes Care 2017, 40, 69-76. [CrossRef] [PubMed] 
12. Mori, H.; Okada, Y.; Arao, T.; Tanaka, Y. Sitagliptin improves albuminuria in patients with type 2 diabetes mellitus. J. Diabetes Investig. 2014, 5, 313-319. [CrossRef] [PubMed]

13. Penno, G.; Garofolo, M.; Del Prato, S. Dipeptidyl peptidase-4 inhibition in chronic kidney disease and potential for protection against diabetes-related renal injury. Nutr. Metab. Cardiovasc. Dis. 2016, 26, 361-373. [CrossRef] [PubMed]

14. Fujita, H.; Taniai, H.; Murayama, H.; Ohshiro, H.; Hayashi, H.; Sato, S.; Kikuchi, N.; Komatsu, T.; Komatsu, K.; Komatsu, K.; et al. DPP-4 inhibition with alogliptin on top of angiotensin II type 1 receptor blockade ameliorates albuminuria via up-regulation of SDF- $1 \alpha$ in type 2 diabetic patients with incipient nephropathy. Endocr. J. 2014, 61, 159-166. [CrossRef] [PubMed]

15. Shi, S.; Koya, D.; Kanasaki, K. Dipeptidyl peptidase-4 and kidney fibrosis in diabetes. Fibrogenesis Tissue Repair 2016, 9, 1. [CrossRef]

16. Hung, A.M.; Roumie, C.L.; Greevy, R.A.; Liu, X.; Grijalva, C.G.; Murff, H.J.; Griffin, M.R. Kidney function decline in metformin versus sulfonylurea initiators: Assessment of time-dependent contribution of weight, blood pressure, and glycemic control. Pharmacoepidemiol. Drug Saf. 2013, 22, 623-631. [CrossRef]

17. Ioannidis, I. Diabetes treatment in patients with renal disease: Is the landscape clear enough? World J. Diabetes 2014, 5, 651-658. [CrossRef]

18. Alicic, R.Z.; Rooney, M.T.; Tuttle, K.R. Diabetic kidney disease: Challenges, progress, and possibilities. Clin. J. Am. Soc. Nephrol. 2017, 12, 2032-2045. [CrossRef]

19. Maric-Bilkan, C. Obesity and diabetic kidney disease. Med. Clin. N. Am. 2013, 97, 59-74. [CrossRef]

20. De Cosmo, S.; Viazzi, F.; Piscitelli, P.; Giorda, C.; Ceriello, A.; Genovese, S.; Russo, G.; Guida, P.; Fioretto, P.; Pontremoli, R. Blood pressure status and the incidence of diabetic kidney disease in patients with hypertension and type 2 diabetes. J. Hypertens. 2016, 34, 2090-2098. [CrossRef]

21. Tervaert, T.W.; Mooyaart, A.L.; Amann, K.; Cohen, A.H.; Cook, H.T.; Drachenberg, C.B.; Ferrario, F.; Fogo, A.B.; Haas, M.; De Heer, E.; et al. Pathologic classification of diabetic nephropathy. J. Am. Soc. Nephrol. 2010, 21, 556-563. [CrossRef] [PubMed]

22. Rafieian-Kopaie, M. Metformin and renal injury protection. J. Renal Inj. Prev. 2013, 2, 91-92. [PubMed]

23. Bowden, D.W. Genetics of kidney disease. Kidney Int. Suppl. 2003, 63, S8-S12. [CrossRef] [PubMed]

24. Macisaac, R.J.; Ekinci, E.I.; Jerums, G. Markers of and risk factors for the development and progression of diabetic kidney disease. Am. J. Kidney Dis. 2014, 63, S39-S62. [CrossRef] 